\title{
La muralla del vendaval de Cádiz
}

\section{José María Sánchez Carrión}

Barcelona, España, josemariasanchezcarrion@gmail.com

\begin{abstract}
Since Felipe II decided to rebuild the city of Cádiz after landing the Earl of Essex in 1596, the city has struggled over four centuries to establish a barrier between the city and the sea to defend her from the terrible storms lift. The remodeling of wall, known by the, was constant between the seventeenth and nineteenth centuries. The council provided specific excises with the Royal Board of Fortifications could perform construction and maintenance. In 1787 Tomás Muñoz, direct marine engineer, was commissioned to make a new project budgeted at 19,800,985 real; although its performance was widely. This project included the construction of an inclined plane, which he called "artificial beach".
\end{abstract}

Keywords: Cádiz, muralla, playa artificial, ingenieros de marina.

\section{Introducción}

La capital gaditana sufría los envites de los temporales de poniente que, sistemáticamente, destruía la playa del sur y derribaba su muralla, que había que volver a reconstruir. Además del coste de sustitución, esta destrucción, suponía un peligro adicional tanto por la vulnerabilidad frente a ataques enemigos, contrabandistas o facinerosos, como para la propia supervivencia de la ciudad que no podía evitar la entrada del mar en sus calles y contaminación de sus aljibes.

La financiación de las obras correspondía en exclusiva del consistorio que recurría a un sistemático aumento de nuevos y mayores arbitrios. La ciudad de Cádiz, primer puerto peninsular en tráfico de mercancías y personas, disponía de arbitrios que permitían a la Real Junta de Fortificaciones la realización de las obras de las murallas o del camino a la Isla de León.

La ciudad pudo resistir numerosos ataques, entre ellos los protagonizados por adversarios tan temibles como Barbarroja; sin embargo en 1596 el almirante Drake con 15.000 hombres y 150 buques, logró vencer la escasa resistencia y desembarcar en el istmo que une con la isla de
León. La ciudad fue destruida totalmente y Felipe II, tras descartar su abandono o convertirla en presidio, decide fortificarla y construir baluartes. De esta época son los de Santa Catalina, San Sebastián, San Lorenzo y Puertas de Tierra. Empezó entonces la lucha para establecer una barrera entre la ciudad y el mar, tarea que ha acompañado a los gaditanos en los últimos 400 años. Como parte de esa barrera se encuentra la muralla del Vendaval, asentada en una cimentación que poco firme, que corre del este al oeste, desde las Puertas de Tierra, hasta el baluarte de Santa Cristina, mirando al mediodía y expuesta por tanto a los vientos de Levante, tal como se indican en las imágenes 1 y 2 .

En 1765, después de los destrozos del temporal de aquel otoño, se solicitó la creación de un nuevo arbitrio. Lo sorprendente fue que en lugar de aprobarse un arbitrio sobre determinados servicios se concedióir autorización para celebrar 120 corridas de toros como se señala en el "Asiento del Reparo de las Brechas de la Muralla del Bendaval y sobre la Rl Concesion de los diez años de Toros a razón de 12 corridas 
cada uno, cuio ingreso se destina pa. dho. reparo" "1 y cuyos ingresos se destinarían a financiar las mencionadas obras.

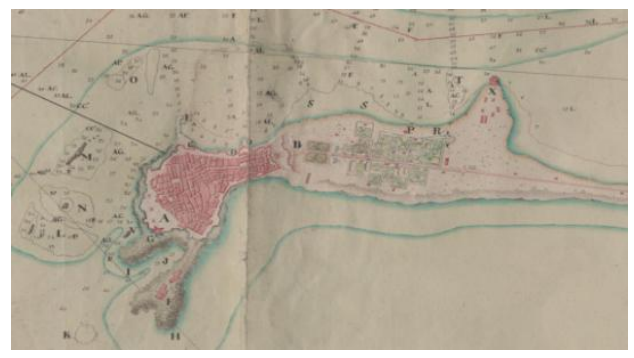

Fig. 1- La ciudad de Cádiz. Detalle del Plano de la Bahía de Cádiz. Escala 1:2000 varas². MNM, E0052.00.30

Años después cuando Carlos IV, en una Real Pragmática de 1790, prohibiría nuevamente las corridas de toros, el cabildo gaditano recurrió a la suspensión diciendo que "el producto de los festejos de toros ha sido uno de los medios ..... por... el que se han construido y conservado las Murallas de esta Plaza.... y que ascendían en el tiempo de su extinción a más de 25 mil pesos anuales" 3 .

Por tan esmerado proyecto y rapidez en la ejecución Muñoz fue premiado el 17 de enero con su ascenso al generalato con el empleo de Brigadier ${ }^{4}$.

Fueron muchos los intentos para encontrar soluciones constructivas durante más de dos siglos hasta encontrar la realizada por el Ingeniero de Marina Tomás Muñoz, conocida como la de la construcción de una "playa artificial".

Esta obra supuso una revalorización de la ciudad de la que Muñoz se siente tan satisfecho que llega a escribir, suponemos que algún sonrojo: "Yo, Señor Excelentisimo, vil instrumento de que se ha valido la Providencia.... ( para construir la muralla) que sirve de tanta utilidad al Servicio del Rey y bien de este Publico, hace honor a toda la nación, y en particular al Cuerpo.......".

Se congratula por el resultado ya que: "los habitantes qe. antes huian horrorizados delos ataques del océano, se presentan hoy llenos de regocija a divertirse en examinar el juego de las olas, como se destruyen unas olas con las otras sin llegar el caso de subir mas qe. Hasta la cresta del parapeto, dejando siempre libre aquel espacioso campo de capuchinos para desahogo de todo el pueblo"6. La obra fue homenajeada, en 1791, por un poema elogio titulado "El Muñoz ó la Hidraulicana" de Manuel Copons.

Muñoz no se olvida en sus escritos a oficiales y trabajadores que habían realizado su trabajo para los que pedía honores y compensaciones ya que : "las casas de aquella parte del Pueblo ... son las mas ventajosamente situadas, han recobrado su estimación ${ }^{8}$.

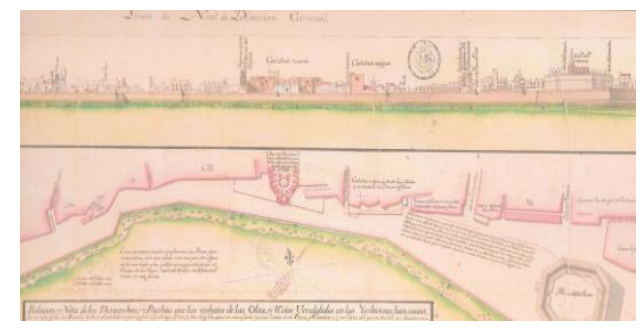

Fig. 2- Detalle del plano de la muralla del Vendaval desde el Matadero, frente a la plaza de toros, hasta el convento de los capuchinos. SHMM, CA 49-04

\section{Proyecto de Tomás Muñoz}

Tomás Muñoz, Ingeniero Director de Marina, y Capitán de Navío, es nombrado Director de las obras de las murallas del sur, debido a su gran experiencia en ingeniería hidráulica por sus trabajos en los muelles y diques del Arsenal de Cartagena y por la feliz finalización del Dique San Antonio del Arsenal de La Carraca cuyas filtraciones habían retrasado casi cuarenta años su puesta en operación.

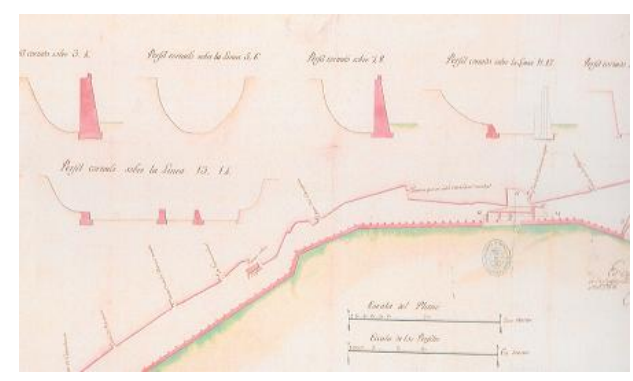

Fig. 3-. Detalle del Plano y Perfiles de los destrozos de la muralla de fecha 06.04.1792. SHMM, CA 30.16 
La muralla había sufrido los efectos de un fuerte temporal y se incluye, en la Imagen 3, un detalle del "Plano y Perfiles de Muralla de vendabal de esta Plaza de Cádiz, que se levantó el 21 de febrero de 1786 manifestando en él todos loa Ahugeros pasantes, brechas desde el Flanco de Capuchinos hasta el del Matadero".

Terminadas las obras del dique de la Carraca Muñoz fue encargado de realizar un nuevo proyecto de la muralla. Este fue desarrollado a lo lago de los tres años siguientes con un presupuesto de 19.880 .985 reales de vellón y se dieron oficialmente finalizadas el 6 de enero de 1792 con un coste cercano a los treinta y un millones y medio de reales, lo que supuso una desviación cercana al $50 \%$ del presupuesto.



Fig. 4- Detalle plano SHMM, CA 51.10

El escaso conocimiento científico del siglo XVIII de los efectos del oleaje dificultó la resolución del problema. Los tratados que se enseñaban en las Academias Militares, entre ellas la de Barcelona, eran los de Bails que es sus tratado de matemáticas y mecánica habla de canalizaciones, esclusas o desniveles, pero nada o muy poco de los efectos del oleaje sobre las murallas y Belidor autor de la Architecture Hydraulique que se considera un tratado clásico de construcción de puertos, faros $y$ construcciones auxiliares.

La proyecto aportaba, como innovación, la construcción de un plano inclinado de $15^{\circ}$ que supuestamente disiparía la energía mareomotriz, incluso con olas rompientes, antes de llegar a la muralla"".

A pesar de que durante aquel invierno las murallas soportaron dos fuertes temporales con destrozos asumibles, Muñoz se queja ante el Ministerio de la Guerra que no le llegan los fondos para la realización de la obra y duda que la falta de caudales del Fondo de Fortificaciones.
La paralización de los trabajos durante el invierno es la justificación de no pagar los trabajos realizados. Razón que Muñoz no se cree, sino que denuncia una trama contra él de los Ingenieros del Ejército por haber asumido unas obras que hasta entonces eran de su competencia. El Conde del Campo de Alange, Ministro de Guerra, exige urgentemente a la Junta que atienda las reclamaciones y advierte que no tolerará en el futuro ataques infundados a dicho oficial ${ }^{10}$.

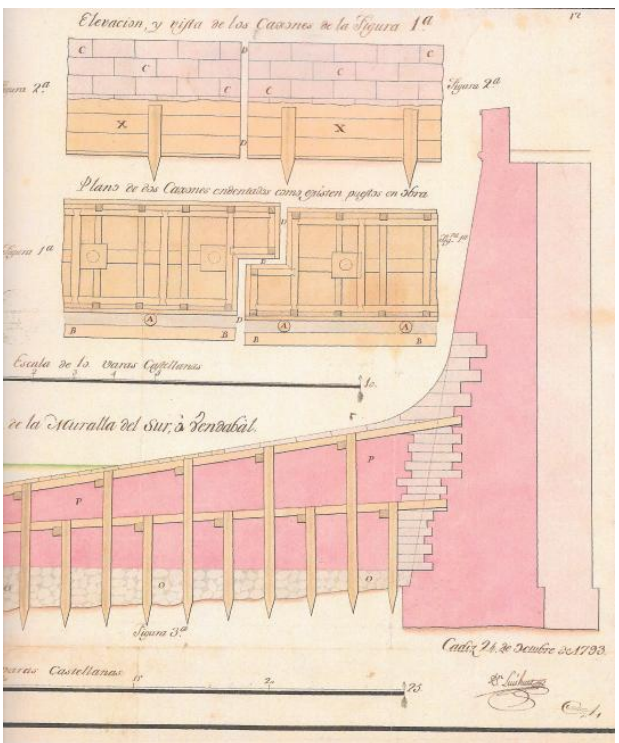

Fig. 5- Detalle plano SHMM, CA 29.05

Para la construcción del trozo de la muralla de 1.050 varas de longitud tuvo que vencer numerosos escollos a base de petardos. Los trozos los sacaban los buzos y se utilizaron para el relleno de la playa artificial. Al pie del muro se procedió al hincado de pilotes de madera atados por tablones en su parte superior. Las obras solo se realizaban de mayo a septiembre y durante las horas de bajamar. El terreno se fue allanando, como se ha dicho. En los huecos existentes entre los pilotes y los tablones que se representan en la imagen 5 se iban rellenado con piedras de un pie cubico, como se indica en la imagen 4. La rampa de cierre tenía una longitud de 24 varas y empezaba a unas 6 sobre el nivel de bajamar para acabar a dicho nivel. La muralla 
tendría finalmente el perfil que se representa en la imagen 6 .

El Rey, en un acto de generosidad a costa del contribuyente gaditano, entiende que sería "mui justo que la ciudad de Cádiz manifieste su gratitud" 11 con respecto al Brigadier y para ello establece una pensión de 27.000 reales para cada una de sus tres hijas pagadas contra el Fondo de Fortificaciones que en aquel momento era de unos 13 millones de reales ${ }^{12}$.. Sin embargo la Junta se niega a ejecutar la resolución real porque entiende que esa carga no correspondía al Fondo ni en el fondo ni en la forma ${ }^{13}$.

A pesar de los plácemes por la obra la realidad es que tuvo un éxito efímero, puesto que en el invierno de 1792 un nuevo temporal abrió una brecha frente el Palacio Episcopal. Por falta de presupuesto no fue reparada y la brecha fue aumentando poco a poco hasta tal forma que en 1813 solo quedaría un ligero recuerdo de la misma.

Estudios posteriores han encontrado las razones técnicas del fracaso, ya que aun cuando se sabía en siglo XVIII que cuanto más grande fuese una piedra mejor resistiría al oleaje; sin embargo no se conocía que en la rotura por fondo de una ola solidaria existe una relación entre la altura de esta y la profundidad en ese punto. Eso llevó a colocar piedras de escaso tamaño, en este caso de una vara cúbica y por el hecho de barrenar los bajos rocosos y dejarlos a poco más de profundidad dejó el conjunto inestable. Las consecuencias dramáticas se hicieron evidentes al poco tiempo. Otro importante fenómeno que era desconocido era las consecuencias de los efectos dinámicos de una fuerza periódica, el periodo del oleaje es entre 5 y 12 seg., sobre los pilotes de madera llegan a producir su rotura al cabo de un tiempo.

Sin embargo en los archivos se encuentran pruebas contradictorias, por una Juan José Muñoz Pérez señala que 1.050 varas fueron destruidas por un fuerte temporal al invierno siguiente, sin embargo Muñoz en su señala que las murallas han resistido y solo se han levantado algunos tablones, descompuesto parte de la mampostería y que algunos bloques han quedado desligados, Muñoz las califica de desperfectos sin mayor importancia y que la muralla ha sido un éxito a pesar de que dicen "algunos mal intencionados del objeto y circunstancia de la obra" $"$.

Cuando el cabildo aprueba no aceptar el pago de las pensiones a las hijas de Muñoz, este inicia un pleito contra el ayuntamiento cuando abre la brecha en el muro; pero antes ya había obtenido del Rey promesa de un agradecimiento posterior.

En enero de 1794 Muñoz presenta un presupuesto para la reparación de la playa artificial y la escollera durante ese ejercicio que suma 460.000 reales de vellón; de los cuales 193.312 serían los necesarios para la playa artificial, otros 213,768 para la escollera y los restantes 52.920 como sueldos y gratificaciones del personal indirecto.

Otra vez vuelven a aparecer las disputas competenciales entre los ingenieros del ejército y los de marina con el apoyo y enemistad del Gobernador de la Plaza que desea que la obra se realice dentro del Ministerio de Guerra ${ }^{15}$.

Las discrepancias entre ministerios e ingenieros perduran y en 1796 se nombra una comisión de ingenieros del ejército y de marina para realizar las inspecciones de la Muralla.

La comisión la forman los Coroneles Ingenieros Fausto Caballero y Domingo Balesta, el Jefe de Escuadra Francisco Javier Rovira y el Ingeniero Director de Marina Fernando Casado y el resultado no es unánime por un lado los ingenieros del Ejército y por otros y separados los marinos. Finalmente Caballero y Rovira firmaron otra resolución separada y por su lado Casado mantiene la bondad de la playa artificial, aunque sugiere pudiera construirse de caso de arena $^{16}$. Fernando Casado en 1820 Comandante General de los Ingenieros de Marina, empleo que alcanzara Muñoz en 1805.

La existencia del Fondo de Fortificaciones suponía un gran alivio a los gaditanos, ya que no veían agravados sus arbitrios después de casa desastre. Sin embargo por las luchas competenciales que se han mencionado entre los distintos cuerpos de ingenieros, los pagos directos al Ingeniero Director se hacían con retraso y en varias ocasiones se quejó al Rey de 
que las asignaciones no le eran suficientes para pagar su sustento ni los viajes a la corte para explicar su proyecto.

En varias veces Carlos IV comprometía su palabra para asegurarle una segura recompensa en la que la "ciudad de Cadiz (mostraría) su gratitud“"17.

Dado que el acuerdo del pago contra el Fondo y la petición de aumento del mismo en 100.000 reales para pagar una renta de 27.000 reales a favor de sus tres hijos no tuvieron efecto, incluso antes las acciones judiciales emprendidas contra el cabildo, el Rey se sintió obligado a compensar a Tomás Muñoz de otra manera con el fin de mantener su firme promesa. El Rey le asciende a Jefe de Escuadra y más tarde a Teniente General y puede que incluso fuese el motivo por el que le nombrase, sorpresivamente, Ingeniero Genera de Marina, en lugar del también Teniente General Julián de Retamosa.

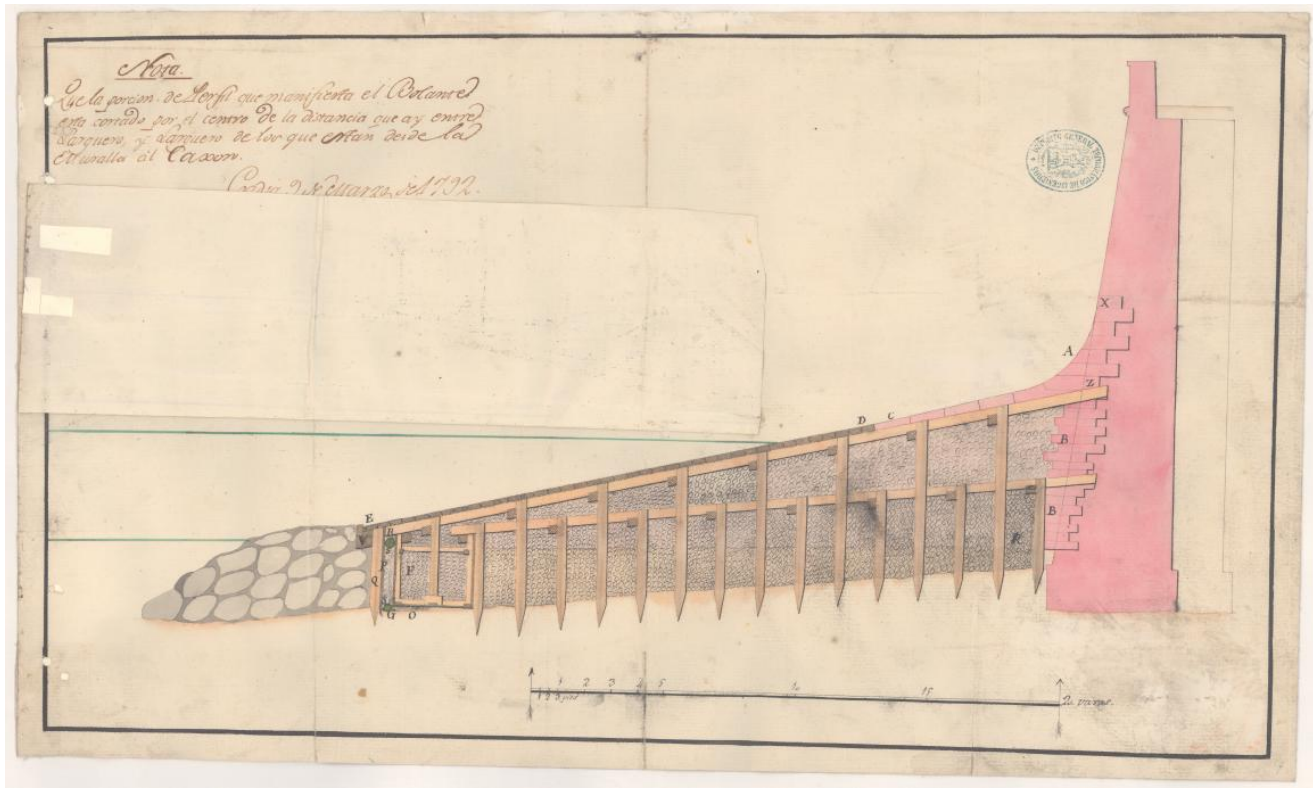

Fig. 6- Perfil transversal de toda la muralla, fecha 24.10.1793. SHMM CA29.10.1

\section{Notas biográficas de Tomás Muñoz}

Tomás Muñoz y Clavera, Teniente del Regimiento de Infantería de América y con estudios en la Academia de Matemáticas de Barcelona, ingresa en el Cuerpo de Ingenieros de Marina en 1777 (creado por R.O del 10.10.1770, mientras que el Cuerpo de los Ingenieros del Ejército en 1711) en la Clase de Extraordinario. De su carrera en el cuerpo puede señalarse que en 1778 fue ascendido a Ordinario, en 1782 en Segundo. En 1785 pasa con grado sobresaliente los exámenes de Matemáticas de Ordenanzas y las Sublimes, lo que le capacita para desempañar cuantas obras y comisiones se le encarguen. En 1786 es ascendió a Ingeniero en Jefe y por último Ingeniero Director en 1790. El 5 de octubre de 1802 obtiene además el empleo de Teniente General de la Armada.

En 1807 tras la dimisión del Ingeniero General de Marina Jose Romero Fernández de Landa, se espera en la Corte el nombramiento del Teniente General Julián Retamosa que llevaba más de 10 años manejando los asuntos de la Comandancia General de Ingenieros ${ }^{18}$. Sin embargo el Ministro de Marina Gil de Lemos le propone al ser el más antiguo del Cuerpo y el Rey lo acepta en cumplimiento de la palabra dada $^{19}$. 
Destinado por su cargo en La Corte, al declararse la Guerra de la Independencia permanece en el gobierno del Rey Intruso del que era Ministro de Marina Josef de Mazarredo. Como muchos militares, por miedo a las represalias, acompaña al Rey al exilio y es internado en el Depósito Militar de Alenson donde pide ser rehabilitado.

Regresa a España en 1820 sin honores y su muerte en 1822 paraliza el expediente de rehabilitación que contaba con el informe favorable del Ministerio Fiscal. Hoy sigue siendo acusado de afrancesado cuando su Ministro Mazarredo, tan afrancesado como él goza de todos los honores y prebendas de un marino ejemplar. Ironías de la historia.

\section{Notas}

(1) AHPC: Sección Protocolos, Notaria 28, Libro 5899, año 1765

(2) Nota: 1 vara $=0,834$ metros

(3) AMC: Actas Capitulares de Cádiz. Cabildo del 17.01.1790, libro 145, fol. 315

(4) AGMAB. Ingenieros. Asuntos Personales. Legajo 3408/48. Carta de Valdés a Romero 17.01.1792

(5) AGMAB. Ingenieros. Ingenieros. Asuntos Personales. Legajo 3408/48. Instancia 06.01.1792

(6) AGMAB. Misma referencia anterior. Instancia 06.01.1792 y Minuta carta de Muñoz a Antonio Valdés 13.01.1792
(7) Nota: Poema no localizado

(8) Misma referencia anterior

(9) AGMAB. Ingenieros. Asuntos Personales. Legajo 3408/48. Carta de Muñoz a Valdés 25.03.1794

(10) AGMAB. Oficiales, Legajo 620/820. Carta al Conde del Campo de Alange de 22.04.1794

(11) AGMAB. Ingenieros. Ingenieros. Asuntos Personales. Legajo. 3408/48 Carta de Muñoz 25.03.1794

(12) AGMAB. Oficiales. Legajo 620/820. Carta 27.08.1793

(13) Misma referencia. Notificación del Ministro de Guerra, 14.01.1794

(14) Misma referencia. Informe Muñoz de fecha 27.12.1793

(15) AGMAB. Oficiales. Legajo 620/820. Presupuesto de Muñoz fecha 17.01.1794

(16) AGMAB. Oficiales. Legajo 620/820. Dictamen 04.06.1796.

(17) ACM. Ingenieros. Ingenieros. Asuntos Personales. Leg. 3408/48 Instancia de Muñoz de fecha 25.03.1794

(18) AGMAB. Ingenieros. Asuntos Personales, Legajo 3409/59. Fecha 21.06.1814

(19) Misma referencia anterior. Fecha 22.04.179

\section{Referencias}

Además los legajos históricos señalados en el texto de los Archivo Histórico Provincial de Cádiz (AHPV), Archivo Municipal de Cádiz (AMC), Archivo General de Simancas (AGS), Archivo del Museo Naval (AMN), Archivo General de Marina Don Álvaro de Bazán (AGMAB) y Servicio Histórico Militar de Madrid (SHMM), se incluye a continuación la siguiente bibliografía.

Alía Plana M. "La Armada y la Enseñanza Naval (1700-1840) en sus Documentos. Aproximación a las Reales Ordenanzas reguladoras, desde una perspectiva jurídico-administrativa y pedagógica": Tesis doctoral.

Cámara Muñoz A. (2005). "Los Ingenieros Militares de la monarquía hispánica en los siglos XVII y XVIII”. Ministerio de Defensa Ed. Madrid

Capel H. (1983). "Los militares en la España del siglo XVIII. Repertorio biográfico e inventario de su labor científica y espacial”. Universidad de Barcelona. Barcelona 
Gallans Seguela M. (2008). “Les ingénieurs militaires espagnols de 1710 à 1803 ”. Casa de Velázquez Ed. Madrid.

Muñoz Pérez J. J. (2009). "Las murallas del Cádiz y su lucha contra el mar". Revista de Obras Públicas: Órgano profesional de los ingenieros de caminos, canales y puertos, $\mathrm{N}^{\circ}$. 3495, pp. 41-52

Muñoz Pérez J.J. (2007). "Los conocimientos de oleaje en las postrimerías del siglo XVIII y su aplicación a la muralla del vendaval en Cádiz”. Actas del quinto congreso nacional de historia de la construcción. Arenillas C. y otros Ed. Madrid

Pavía, F. de P. (1874). "Galería biográfica de los generales de marina, jefes y personajes notables que figuran en la misma corporación desde 1700 a 1865”. J López Ed. Madrid

Sánchez Carrión J. M. (2009). "Los Ingenieros de Marina motores de la renovación y tecnificación de la construcción naval española (1770-1827). Su organización, Academia y Realizaciones”. (Tesis doctoral UPM-2009 no publicada) 
